\title{
DEVELOPMENT OF A ZULU SPEECH RECEPTION THRESHOLD TEST FOR ZULU FIRST LANGUAGE SPEAKERS IN KWA ZULU-NATAL
}

\author{
Seema Panday, Harsha Kathard, Mershen Pillay \& Cyril Govender
}

\author{
Discipline of Audiology \\ School of Audiology, Occupational Therapy and Speech-Language Pathology \\ University of Kwa Zulu-Natal
}

\begin{abstract}
The measurement of speech reception threshold (SRT) is best evaluated in an individual's first language. The present study focused on the development of a Zulu SRT word list, according to adapted criteria for SRT in Zulu. The aim of this paper is to present the process involved in the development of the Zulu word list. In acquiring the data to realize this aim, 131 common bisyllabic Zulu words were identified by two Zulu speaking language interpreters and two tertiary level educators. Eighty two percent of these words were described as bisyllabic verbs. Thereafter using a three point Likert scale, 58 bisyllabic verbs were rated by 5 linguistic experts as being familiar, phonetically dissimilar and being low tone verbs. According to the Kendall's co-efficient of concordance at $95 \%$ level of confidence the agreement among the raters was good for each criterion. The results highlighted the importance of adapting the criteria for SRT to suit the structure of the language. An important research implication emerging from the study is the theoretical guidelines proposed for the development of SRT material in other African Languages. Furthermore, the importance of using speech material appropriate to the language has also being highlighted. The developed SRT word list in Zulu is applicable to the adult Zulu First Language Speaker in KZN.
\end{abstract}

Key words: speech reception threshold, Zulu First Language Speaker, SRT word list development, familiarity, phonetic dissimilarity, low tone verbs

\section{INTRODUCTION}

The Speech Reception Threshold (SRT) test is part of the initial conventional audiological test battery. SRT is defined by the (American Speech and Hearing Association [ASHA], 1988) as the hearing level in decibels $(\mathrm{dB})$ at which the individual can respond correctly to $50 \%$ of the test words presented to him/ her. However, in order to recognize and understand the test words the individual should be familiar with the words (Lyregaard, 1997). Therefore, Balkisson (2001) suggests that it is best achieved if the test materials used are presented in a language in which the individual is most familiar, i.e. in his/her first language. Furthermore, testing patients with materials recorded in a language other than their native tongue would "adversely affect performance and interpretation of results" (Nissen, Harris, Jennings, Eggert \& Buck, 2005, p. 392).

In considering the above recommendation, there is a need for linguistically matched, easily understandable and highly familiar words for the establishment of SRT in Zulu. The need for linguistically matched speech materials has motivated many researchers to embark on the formidable task of developing word lists in the client's mother tongue language. Some of these researchers include, Ashoor \& Proschazka (1985) who developed test words in Arabic, Plant (1990) focused on the development of words in Walpiri and Tiwi; and more recently, Nissen et al. (2005), who developed words in Mandarin. Nissen et al. (2005) also strongly argued that to develop a suitable word list in a language other than English requires an in-depth understanding of the linguistic structure of the language because the criteria for the original English SRT materials have been designed around the structure of English. It is also well known that each language has its own linguistic structure. Therefore, the rules governing one language may not always be applicable to other languages. Hence, it was deemed necessary to develop a word list that was relevant to the Zulu language in Kwa Zulu-Natal (KZN).

The need for linguistically-matched speech materials for Zulu First Language Speakers (ZFLS) is a reality when considering the demographic profile of KZN. Zulu is the first language of $80 \%$ of the 9.426 million people in KZN (Population Census, 2001). In fact, Zulu is the Nguni language spoken by almost 8.5 million people in the whole of South Africa (Grimes, 1992). Zulu is also one of the eleven official languages of South Africa. The concentration of Zulu speakers is, however, in KZN. In spite of Zulu speakers being the majority of the population of KZN, the development of linguistically appropriate materials has been lacking. Speech audiometry, like most other areas of speech, language and hearing services in South Africa, has a paucity of relevant test materials to evaluate the majority of the individuals who do not speak English as their first language (Bortz, 1992). As a consequence the service provided to African first language speakers of $\mathrm{KZN}$ is poor (Pillay, Kathard and Samuel, 1997). In order to address this shortcoming, appropriate and relevant tools should be developed and made available for clinical use.

The lack of carefully developed Zulu materials has resulted in audiologists following one of three trends in current practice in KZN. John (1990) indicates that speech reception testing is omitted from the initial test battery, or that the SRT is obtained using the Standard English material viz. Central Institute for Deaf CID WI and W2 spondee word list. Finally, SRT is obtained using modified methods and non-standardized randomly selected bisyllabic words in Zulu. However, according to Nissen et al. (2005), the use of such materials could affect the performance and interpretation of the results. Thus casting doubt on the validity of the test. The underlying reason for this is that one of the most important characteristics of SRT materials and SRT testing is familiarity of stimuli to the client (Carhart, 1965). Furthermore, Knight (1997) warns that developing linguistically matched word lists should be based on specified criteria such as familiarity of the words in the language.

In addition, Rudmin (1987) also stated that each nation's linguistic milieu should be considered when offering 
speech audiometry services. The current practice of using English material or randomly selected bisyllabic words for the assessment of SRT in Zulu is problematic and a more valid tool is required. Clearly, the inappropriate practice in the current context provided the rationale for the development of a word list in Zulu.

Furthermore, the measurement of hearing threshold for speech is integral to the comprehensive diagnostic evaluation of hearing (Ramkissoon, Proctor, Lansing, Bilger, 2002). This is so since the understanding of speech is an important human faculty and the speech signal according to Martin (1997) forms the basis of auditory stimulation that occurs in everyday life. Young, Dudley \& Gunter (1982) and ASHA (1988) also assert that speech audiometry evaluates the listener's ability to hear, recognize and understand speech communication in the everyday environment.

In addition speech audiometry, inclu ding SRT testing, complements the other conventional tests of audiometry, such as pure tone audiometry. It is well known that pure tone audiometry provides the 'gold standard' for the initial audiological assessment of hearing (Roeser, Valante \& HorsfordDunn, 2000) Nonetheless, while pure tone thresholds are important in predicting the hearing patterns at discrete frequencies, the speech threshold test is able to provide a more comprehensive and realistic description of hearing in everyday life. Nissen et al. (2005) explains that speech testing contributes more information about the hearing impairment of an individual than do pure tones.

Moreover, Gelfand (1997) reported on the clinical value of SRT which is described as, SRT quantifies the listener's hearing level for speech. SRT also serves as a validity check for pure tone audiometry. SRT provides diagnostic and prognostic value to the total audiometric test battery and is the reference point for suprathreshold speech tests. SRT has also serves as a tool to assess medical, surgical and rehabilitative intervention. The clinical value of SRT testing, confirms its importance in the test battery. Therefore, in view of the important clinical value, developing appropriate materials for SRT testing is clearly warranted.

The focus of this paper therefore is on the process towards the development of a word list for ZFLS in KZN, with specific emphasis on the key theoretical considerations that emerged during this process. This aspect was one of three aims that were a part of a larger study conducted by Panday (2006). However, for the purposes of this paper the development aspect of the SRT word list is presented. The nature of the topic under discussion also required reference to several seminal references and current literature.

In order to develop materials for the establishment of the SRT in ZFLS, there should also be an understanding of how speech is perceived. Lyregaard (1997) explains speech perception as a pattern recognition process where the listener hears certain acoustic cues and selects the appropriate category where the item fits. The important aspect of this selection is that it is not only based on acoustic or phonetic factors, but also on the syntax, semantics and the overall context (Lyregaard, 1997).

It is therefore clear that the perception of speech is a complex task. The context, semantic, syntactic cues and the cognitive resources of the listener assists in the processing of the signal. Therefore, most listeners are able to perceive the signal under difficult listening conditions. The implication of contexts is best seen when words are presented to individuals acquiring a second language (Criag, 1997). Identical speech signals presented to one group of listeners who are first language speakers and to those who are second language speakers results in latter group being unable to hear subtle sounds segments and prosodic nuances. First language listeners however are able to appreciate these differences (Criag, 1997). Words having a higher frequency of occurrence are more easily recognized than those that have a lower frequency of occurrence.

This is particularly relevant for the development of the materials in Zulu. The ZFLS would be more familiar with the Zulu words from both the acoustic properties of the words and the prosodic, semantic and lexical aspects. These elements facilitate easier recognition of the words when the stimulus is closer to threshold.

In view of the foregoing argument on the influence of both contexts and the acoustic properties of the language on the perception and understanding of speech, the process towards the development of a suitable SRT word list in Zulu has to also be guided by the rules that govern the language.

Zulu is an Nguni language. The Nguni languages are part of a larger related group of South Eastern Bantu languages. In terms of structure, Zulu is an agglutinative language, which commonly has roots bound to prefixes and suffixes (Jacobson \& Trail, 1986). The root of the word usually carries lexical meaning. The word structure without the prefix and suffix would be purely a bisyllabic word in the consonant vowel, consonant vowel sequence (CVCV), e.g. /hamba/ meaning "to go" in English. This word form only appears as a verb imperative and hardly ever as a noun. Noun classes in Zulu are often trisyllabic in nature because of the prefix formative e.g. /ihashi/ meaning "horse' in English (Jacobson \& Trail, 1986). This aspect of the language had to be carefully considered, as the type of stimuli selected for the SRT material in Zulu is dependent on the availability of stimuli in the language.

An important consideration therefore, with regard to the development of the word list, relates to the type of stimuli to be considered. Historically researchers focused on developing SRT words that were bisyllabic and equally stressed, known as spondees (Silman \& Silverman, 1991; Gelfand, 1997). The main advantage of using spondees centered on the need for words to have equal stress on each syllable. This allowed for uniformity and precise testing. On the contrary, Hodgeson (1980) stated that spondee words were not so common in English since the stress of bisyllabic words is usually placed on the first syllable. Many words such as, "baseball", "hotdog", "cowboy' easily satisfied the criterion if care was taken to stress the first' syllable. The change in stress pattern is permissible in English and does not alter the meaning of the word. Therefore, several words of this structure were selected for the original word list. However, while Zulu is able to satisfy the criterion of bisyllabic words, the use of equally stressed words is unavailable structurally. This is so since Zulu is a "non-stress" language where stress is not used to indicate emphasis nor is used to differentiate words or syllables as seen in English (Cope, 1982).

Furthermore, unlike English, the introduction of artificial stress patterns on each syllable in Zulu could possibly alter the meaning of the words. This is so since Zulu is a tonal language (Rycroft \& Ncgobo, 1979). Tonal variations are lexically significant in Zulu (Rycroft \& Ncgobo, 1979), implying that the pitch of the word corresponds to the difference in meaning. To illustrate, the word /inyanga/ can mean "doctor" or "moon" or "month" depending on where the pitch of the word occurs. The role of tone has three distinct functions in Zulu, i.e. semantic (affecting the meaning of words), grammatical, and emotional (Cope, 1982). These tonal variations may influence the meaning of the stimuli, thus having implications for speech understanding.

If Zulu does not have the linguistic characteristic of 
equally stressed words, then the criteria for SRT materials needs adaptation or the development of new criteria to suit the structure of the language is required. This point of view has been widely supported by studies conducted in languages other than English, e.g. Plant (1990) who developed the Tiwi and Walpiri word lists, and Nissen et al. (2005), who developed Mandarin word lists. Studies such as these emphasize important theoretical considerations regarding the structure of the language at a lexical, phonological and syllable level. The Tiwi and Walpiri languages were found to have a different stress pattern to that of English i.e. the stress of the word is usually placed on the penultimate syllable, (Plant, 1990). These structural differences therefore required adaptation of the original SRT criteria.

Nissen et al. (2005) also supported the notion adapting the original SRT criteria to suit the structure of the language. Nissen et al. (2005) concluded that 24 trisyallbic Mandarin words could be utilized to measure an individual's SRT if the native language was Mandarin. Their study showed highly favorable results when the trisyllabic words were assessed, with results comparable to those of English.

Locally the literature with regard to word list development is in its infancy. However, the issues raised in the some of the African and South African studies support the contention made in the present study. Chetty (1990) reported that the choice of bisyllabic words and the tone of the words appear to be critical to the overall development of a Zulu word list. In fact, the abundance of commonly used bisyllabic verb imperatives with low -high tones in Zulu was considered a suitable option for SRT word list development in Zulu (Chetty,1990) As consequence of Chetty's work it was considered necessary to evaluate the low tone, bisyllabic verbs under more stringent methodological conditions.

Closer inspection of the historical criteria for SRT word list development suggested by Hudgins, Hawkins, Karlin \& Stevans in 1947 confirms the need for adaptation or review of these criteria to suit the language of Zulu. These criteria include familiarity, phonetic dissimilarity, and homogeneity with respect to audibility or intelligibility.

Familiarity refers to the choice of vocabulary used. However, on perusal of the literature the concept of familiarity is explained on the basis of two perspectives viz, familiarity as it relates to the test product (word list) and familiarity as it relates to the test process (Testing), (Kruger \& Kruger, 1997). For the purpose of this study an acceptance of both these concepts are considered. Wilson \& Margolis (1983) explained familiarity as it relates to the test product. These authors explain that words selected for the SRT test must be based on the number of times the listener uses the word in everyday speech. To this end, the above authors claim that the most commonly used words are considered to be the most familiar words. Thus, familiarity has remained an important criterion for the development SRT words. There is both historical and current acceptance amongst researchers to include familiarity as a criterion. This has been repeatedly reinforced in the historical and current literature (Hirsh, Silverman, Reynolds, Eldert \& Benson, 1952; Wilson \& Margolis, 1983; Young et al, 1982; ASHA, 1988; Ramkisson, 2000; Nissen et al., 2005). Familiarity is "arguably one of the most important criteria to be considered in word list development" (Nissen et al., 2005, p. 1). This position is also supported in the present study, as common and familiar words are available in the Zulu language.

However, researchers must be cognizant of what makes a word list familiar. The "inherent flexibility of the human language causes it to be extremely variable and changes over time", (Akamajian, Demers, Farmer \& Harnish, 1990, p. 265).
Therefore, it is reasonable to suggest that the shelf life of the words chosen must be considered. Vocabulary within a language is ever changing and expanding according to the influences of a changing society (Fromkin \& Rodmin, 1993). Thus, despite familiar words being available in Zulu, careful considerations of how words are selected to represent this criterion is important. The concept of familiarity within the English language was addressed by consulting a formal list such as the list of word frequency compiled by Thorndike and Lorge, (1944) as cited in Jacobson \& Trail (1986). This method of selecting words has assisted researchers such as Hirsh et al. (1952) to apply this criterion. There is however, a paucity of adequate tools for the Zulu language (Jacobson \& Trail, 1986). Therefore, the need for alternative methods of selecting common familiar words is advisable. Jacobson \& Trail (1986) suggested the utilization of informal methods, such as consulting language educators and linguists. This method is well supported in the literature by Plant (1990) who suggested utilizing highly skilled linguists to assist with the complexities in the language when word lists are being developed. Consequently, the use of speakers of the language and linguistic experts allows for words to be more representative of the language at any given time as compared with making mere references to the dictionary.

In addition to the way words are selected, the criterion of familiarity is also influenced by other socio- linguistic aspects e.g. borrowed words in a language. Many of the African languages spoken in South Africa have been historically influenced by dominant languages such as English and Afrikaans. These languages were predominantly spoken in the educational, technical, commercial and industrial spheres (Jacobson \& Trail, 1986). The inclusion of borrowed words in a list allows for the word list to be applicable to the majority of the Zulu - speaking people in KZN. Familiarity as a criterion is relevant, but the socio-linguistic factors relevant to each language, such "shelf life" of vocabulary and borrowed words must also be considered.

The complexity of satisfying historical criteria in mother tongue languages is further demonstrated when the concept of phonetic dissimilarity is reviewed. Hudgins et al. (1947) as cited in Silman \& Silverman (1991), suggests that the test material must consist of stimuli that vary in terms of consonant and vowel combinations within the language being used. Phonetic dissimilarity in a word list prevents confusion between words (Silman \& Silverman, 1991). However, this criterion has not received the attention that other criteria such as familiarity and homogeneity of audibility has received. This could perhaps be related to the difficulty in satisfying this criterion in languages that have fewer consonant and vowel combinations. The basic five vowel system in Zulu could possibly influence the criterion of phonetic dissimilarity and may require adaptation accordingly. However, the complex consonant system, with the addition of the click sounds that appear frequently in the vocabulary of Zulu, which has implications for the development of the word list i.e. inclusion of click phonemes in the word list may influence the variability of phoneme choices in the words.

The foregoing discussion indicates that key theoretical considerations have been raised and these have implications for the development of an appropriate Zulu word list. The word list development in this study, therefore, was based on the interaction of both the socio-linguistic and structural aspects of the language. Moreover, the need to adapt the original criteria for SRT words to suit these theoretical principles is warranted and is well supported in the literature.

Thus, in view of the uniqueness of SRT, its contributing value to the conventional test battery and the structure of the 
Zulu language the need to develop an appropriate SRT word list for the ZFLS in KZN is justified. In so doing the linguistic needs of the clients serviced by audiologists in KZN would be appropriately met. Therefore the aim of this study was to develop a SRT word list for ZFLS in KZN and to answer the following critical question "What is the process involved in establishing appropriate criteria for the development of a SRT word list for ZFLS in KZN?

\section{METHODOLOGY}

\section{Aim}

The aim of the study was to develop a Zulu word list for SRT testing. This aim generated two objectives i.e.

\section{Objectives}

- To identify commonly used bisyllabic Zulu words and secondly

- To rate the commonly used bisyllabic Zulu words according to the adapted SRT criteria for Zulu viz: Familiarity, phonetic dissimilarity, and tonal patterns of the words.

\section{Study Design}

The design strategy adopted for this aim of the study was a descriptive-survey design. A descriptive-survey design was considered a suitable choice because it focused on describing the process involved in the establishment of appropriate criteria relevant to the development of a SRT word list in Zulu. Hence, a survey approach and a rating strategy were adopted to realize this aim. The descriptive design "describes a situation as it is" in order to gain more information (Leedy \& Ormrod, 2005, p. 179). Thus, for this aim the researcher was concerned with describing the development of an SRT word list for Zulu. In the process, relevant language specific information about the suitability of criteria to be used in the selection of Zulu words was explored. This aim was realized through two distinct objectives. Objective one and two incorporated the criteria for selecting SRT words i.e. identifying bisyllabic Zulu words that were common and ensuring that the words met the criteria of familiarity, phonetic dissimilarity and low tone verb imperatives.

\section{Obiective 1: The identification of commonly used bisyllabic Zulu words for adult ZFLS in KZN}

\section{Participants}

Two Zulu language educators from a tertiary institution and two Zulu language interpreters were considered for this objective of the study. Four participants were considered adequate because the word pool generated at this stage of the study was rated and validated by linguistic experts in objective 2 of the study. The educators and interpreters were selected through purposive sampling, as they were most familiar with the use of the Zulu language as spoken by the adult population on whom the new word list would be used. The educators were also familiar with Zulu as a language, since it is their subject of specialty. The interpreters used the language daily and are familiar with Zulu as a language in the KZN community specifically the dialect spoken in the Greater Durban and Pietermarizburg region.

\section{Selection criteria for the participants} tors were;

The criteria for the selection of the Zulu language educa-

- The educators had to speak Zulu as a first language
- The educators needed to have at least five years of tertiary teaching experience.

The criteria for the selection of the Zulu language interpreters were:

- The interpreters had to be Zulu First language speakers.

- They had to reside in Kwa Zulu-Natal (Durban, Pietermarizburg region) for more than five years.

- The language interpreter had to have passed Grade 12 as a minimum academic qualification.

The above criteria ensured that the participants had sufficient experience with the language. Their experience would thus favorably influence the word choices made in terms of the commonality of the words.

\section{Sampling method}

The purposeful sampling technique was used to select the participants for this objective of the study. Purposive sampling allowed the researcher to choose a sample that represented some feature or process in which the researcher was interested in (McMillan \& Schumacher, 2001; Leedy \& Ormrod, 2005). Therefore, this method was selected, as the participants chosen were representative of the linguistic group for which this word list would be relevant to i.e. ZFLS in KZN. Furthermore, the participants were informed of the topic of interest i.e. Zulu word selection.

\section{Selection criteria for the words}

The criteria for selection of the words included, commonly used bisyllabic words in Zulu. For the purposes of this study, common words refer to the most frequently used bisyllabic words in Zulu in the Durban, Pietermarizburg region of Kwa-Zulu-Natal. The linguistic structure of Zulu permitted the selection of bisyllabic words. Further, Zulu has many bisyllabic words that can be considered common and would satisfy the requirements of an SRT word list (Chetty, 1990). The words considered as being common had to also be identified by two or more participants.

\section{Data collection instrument}

A modified word identification schedule (Appendix A) adapted from (Balkisson, 2001) was provided to each participant to record the chosen words. The use of the word identification schedule ensured that a standard method of recording the words was maintained across all four participants.

\section{Data collection process}

Ethical clearance was obtained from the University of Kwa Zulu-Natal Ethics committee. Permission from the head of the department of Zulu of a tertiary institution was subsequently sought to gain access to the Zulu language educators. The interpreters, however, were approached personally with regards to their participation, outside of their formal work time. Informed consent from the language educators and interpreters was obtained regarding their willingness to participate in the study. The language educators and interpreters were advised on the nature of the study via a meeting with each participant independently. An instructional letter concerning objective 1 was provided to each participant. Each participant was asked to identify a separate list of bisyllabic Zulu words commonly used by ZFLS in KZN (Durban, Pietermariźburg region). A minimum of one hundred words per participant was required. One hundred words per participant ensured that the final list was not too small in terms of the set size. This decision is in keeping with the suggestion made by Punch \& Howard (1985). 


\section{Analysis}

The words were extracted from the identification schedule and captured onto an Excel spread sheet. The spreadsheet was designed to represent each participant's response in terms of the words identified. All words were arranged alphabetically on the spreadsheet. The researcher manually extracted those words that met a fifty- percent or more inclusion criteria. This implies that if a word was suggested by two or more of the participants, the word was included for the next objective of the study. The fifty- percent or more criterion is also known as the two-word selection criteria. This method of inclusion and exclusion has been recommended for word selection by (Madden, 1996). Those words that did not meet the $50 \%$ inclusion criterion were excluded from the study.

Descriptive statistics were used to analyse the most common words suggested by the respondents. Frequency counts, bar graphs and pie charts were among the tools utilized. These techniques indicated the most and least commonly identified words (Mcmillan \& Schumacher, 2001). A second level of analysis included the categorization of the words into different word classes selected i.e. nouns, verbs, adjectives, pronouns etc. Percentage counts were used to describe the word class distribution. After careful analysis of the words using the inclusion and exclusion criteria stipulated above, the common bisyllabic words selected were included in objective two of the study viz.: selection of the words according to the adapted SRT criteria for Zulu.

\section{Objective 2: Selection of words according to the SRT crite-} ria that suited to the Zulu language.

\section{Participants}

Five linguists from two tertiary institutions in KZN participated in objective two of the study. For this objective, the linguists rated the words selected in objective one according to the following criteria i.e. a) familiarity, b) phonetic dissimilarity and c) low tone bisyllabic verb imperatives.

\section{Selection criteria for participants}

The participants had to' be linguists who were knowledgeable in Zulu phonology and the linguistics of Zulu. They had to be familiar with the dialect of Zulu spoken in DurbanPietermarizburg region of KZN. The linguists had to have a masters degree in linguistics as a minimum qualification. This was in keeping with the recommendation by Plant (1990) who reported that the use of highly skilled linguistic experts is required in development of a word list.

\section{Sampling method}

Purposeful non-probability sampling was also used for this objective of the study. Purposive sampling allowed the researcher to select linguists who were represented as experts in the field of Zulu.

\section{Data collection instrument}

An instructional letter accompanied with the three rating scales i.e. rating scale for familiarity, low tone verbs, phonetic dissimilarity of the hundred and thirty one words (131) selected in objective one were presented to each of the linguists (see Panday, 2006). The three point Likert scale was used. The scaling system chosen was similar to most studies of this nature (Hirsh et al. 1952; Madden, 1996). This Likert scaling method represented e.g. the most familiar, fairly familiar and very unfamiliar words in the list. The scaling system was rank ordered and could also be described as a graphic numerical scale. This scale allowed for accurate description of beliefs and opinions in terms of familiarity (Mcmillan \& Schumacher, 2001). The three point scale as opposed to a five point or seven point scale was considered due to the nature of the task. The researcher was concerned with identifying the most familiar words versus the most unfamiliar words in the list. Therefore, the limited rating options provided to the linguists prevented the linguists from providing too many unsure responses.

The items on the scale were presented down the lefthand side of the scale with 1,2 , and 3 in the column adjacent to each word. This format allowed for uncomplicated and relatively quick completion of the task, whereby the participants had to tick in the appropriate column or merely selected the number that represented their opinion.

\section{Data collection process}

Ethical clearance was obtained as described in objective one above. The researcher obtained informed consent from each of the linguists in order for them to participate in the study. A meeting was held with all linguists to provide them with an instructional letter informing them of the nature of the study and the requirements for this objective. Each linguist was presented with the rating scale of the one hundred and thirty one words selected in objective one. The words were rated according to chosen criteria. The linguists worked independently so that personal judgments could be made. In order to control for procedural variables the same set of instructions were presented to all participants as per the instructional letter. Prior to confirming participation in the study, the length of the scale was discussed with all participants, so as to minimize the loss of interest during its completion. It was emphasised that this was not a test and that there were no right or wrong answers. The data obtained were then analysed.

\section{Analysis of data}

Data were analyzed using a quantitative analysis approach. All statistical procedures and analysis were carried out using the SPSS version 11.6 computerized statistical program. The statistical analysis was completed under the advisement of a statistician (Ms. Cathy Connolly \& Ms. Rebecca Shunmugam) at the Medical Research Council of South Africa in Durban in August 2006.

Mean scores were calculated so that the degree of familiarity, phonetic dissimilarity and low tone verbs could be measured across all raters. The words that achieved an average rating of 1.5 or less on all of the criteria, as indicated in previous studies (Hirsh et al. 1952; Madden, 1996) were to be selected. Mean scores are calculated by adding all the scores and dividing by the number of scores (Leedy \& Ormrod, 2005). The mean is the most frequently used measure of central tendency (Mcmillan and Schumacher, 2001).

In addition the Kendall's co-efficient of concordance was used to assess inter-rater reliability. The rationale for the use of the Kendall's test was to determine the extent to which the raters agreed about what they rated (McMillan \& Schumacher, 2001). The Kendall's Coefficient of concordance estimates agreement among multiple raters for ordinal responses as indicated in this study. Kendall's statistic is a measure of the association among appraisers' ratings (Kendall \& Babington-Smith, 1939). Kendall's statistic therefore can only be used when the data has three or more possible levels with natural ordering, such as strongly disagree, disagree, neutral, agree, and strongly agree. Therefore, this test of inter-rater reliability was suitable because the present study utilized three levels of natural ordering. The following table illustrates the values in terms of 
strength of the agreement when Kendall's W score is considered. Table 1 was used in the interpretation of the Kendall's W score in this study.

The coefficient was calculated using the SPSS version 11.6 and a $\mathrm{W}$ score was calculated. A score between 0 tol was regarded significant in terms of overall inter-rater reliability. This score assisted the researcher in terms of overall strength of the information received from the participants. It also confirmed that there was consistency in the measurement or rating of the words. After careful analysis using the above procedures, the words were selected.

\begin{tabular}{|c|c|c|}
\hline $\begin{array}{c}\text { Value of } \\
\text { kappa }\end{array}$ & $\begin{array}{c}\text { Value of } \\
\text { Kendall }\end{array}$ & $\begin{array}{c}\text { Strength of } \\
\text { agreement }\end{array}$ \\
\hline$<0.20$ & -1.0 to -0.2 & Poor \\
\hline $0.21-0.40$ & -0.6 to -0.2 & Fail \\
\hline $0.41-0.60$ & -0.2 to 0.2 & Moderate \\
\hline $0.61-0.80$ & 0.2 to 0.6 & Good \\
\hline $0.81-1.0$ & 0.6 to 1.0 & Very Good \\
\hline
\end{tabular}

Table 1: Values representing strength of agreement for Kendall's W score.

\section{Reliability and Validity}

The following considerations were made to ensure reliability and validity for this aim of the study and for the larger study conducted by Panday (2006). With regards to reliability all participants were provided with the same instructions regarding their role in the study, the data obtained for this aim and for the larger study were verified by linguistic experts. The rating scales used were standard across all raters. Further, the Kendall's coefficient of concordance was used to assess reliability and consistency among the raters. Considerations related to validiy of the results were ensured by the overall two phase methodological approach of the Panday (2006) study. The words were developed and assessed based on both audiological and linguistic principles.

\section{RESULTS AND DISCUSSION}

A total word pool of five hundred and five common words was obtained from the four participants. The average number of words identified per participant was 126 words. The number of words identified ranged from 123 to 133. Appendix B, illustrates the words suggested by each participant. Many of the words obtained by each of the four participants were repeated by more than one participant. The 505 words were categorized for inclusion and exclusion in terms of a $50 \%$ inclusion criterion. One hundred and thirty one words of the 505 words $(26 \%)$ met the inclusion criterion. Seventy four percent of the words were excluded. Appendix B illustrates the distribution of the 131 words according to the number of participants that suggested the words for objective one. There were 57/131 words that were suggested by two participants. Three of the participants suggested 52/131 words and 22/131 words were suggested by all four of the participants. However, all of the 131 words pre-selected were included in objective 2 of the study. The 131 words identified were further categorized in terms of the characteristics of the words identified. Figure 1 illustrates the percentage of words according to the word classes.

The majority $(82 \%)$ of the words chosen were bisyllabic verbs with pronouns being $(6 \%)$, adverbs $(5 \%)$, con-
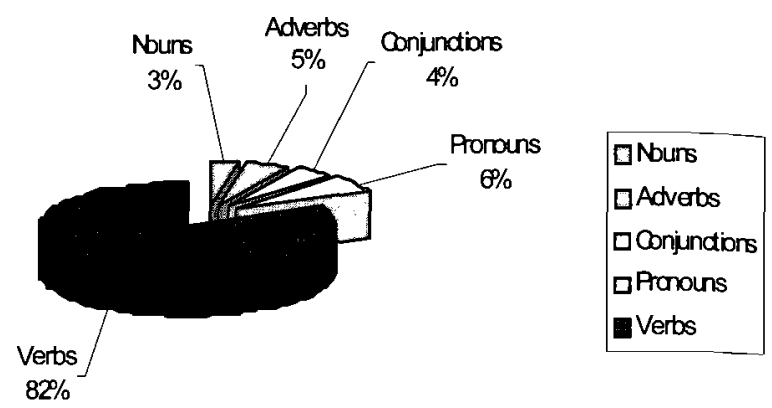

$82 \%$

Figure 1: Pie chart illustrating the percentage of the words according to word classes

junctions (4\%), and nouns $(3 \%)$ respectively. Examples of words within this distribution can be found in Table 2 . These findings are in accordance with the linguistic structure of Zulu. The majority of bisyllabic words in Zulu are verbs rather than nouns ( $R$. Bailey personal communication, April, 2006). The Nguni languages like Zulu and Xhosa share this linguistic feature (Jacobson \& Trail, 1986).

Bisyllabic nouns in Zulu are few because most noun classes have a prefix formative e.g. / ubisi/ meaning milk in English. Thus, the syllable structure becomes trisyllabic. The present study considered the use of bisyllabic verbs. This decision was based on the abundance and availability of bisyllabic verbs in Zulu compared to the paucity of bisyllabic nouns.

Further, the majority ( $82 \%$ ) of the words pre-selected within the present study was verbs. It was also necessary to maintain uniformity in the word classes of the words. For objective two, the 131 words were rated by the linguists, so that careful decisions were made to exclude words that were not verbs. The words were only adjusted on the basis of the results of objective two.

The five-hundred and five bisyllabic words generated at this stage of the study appeared adequate, even though many of the words were repeated across the four participants. This was in accordance with the Madden (1996) study that generated 720 familiar words using similar methods of word pool generation, as in'dicated in the present study. The large word pool at the preliminary phase of the study prevents the final word list from being limited in number. The overall number of words selected has been documented as an important consideration for researchers and clinicians. This follows the argument that SRT scores improve significantly if there are a limited number of SRT words (fewer than 36 ) in the final word list (Punch \& Howard, 1985). The underlying reason for the improvement is related to the possible learning effect as would be the case if there are too few words. Therefore, to prevent the learning effect, the present study supports the above contention of generating a large pool of words.

Table 2: Examples of bisyllabic words according to their different word classes

\begin{tabular}{|l|l|l|l|l|}
\hline $\begin{array}{c}\text { Bisyllabic } \\
\text { Veros }\end{array}$ & Pronouns & Adverbs & $\begin{array}{c}\text { Conjune- } \\
\text { tions }\end{array}$ & Nouns \\
\hline Bhala & zake & Lapha & Fúthi & Nyama \\
\hline Gxeka & zabo & Phansi & & Nyanga \\
\hline Khanya & & Phezu & & \\
\hline Geza & & Muva & & \\
\cline { 1 - 3 }
\end{tabular}


ing effect, the present study supports the above contention of generating a large pool of words.

The exclusion of $74 \%$ of the words could possibly be related to the methodological choice made within the study i.e. only common words were selected. The literature however is not explicit about standard methods used. Knight (1997) suggests that words must be selected after careful analysis of written texts, articles and national radio and television newscasts. Furthermore, studies such as Hirsh et al. (1952) used dictionaries and word resources such as the thousand most common words spoken in a language. The use of dictionaries and word resources has been known to historically generate large word pools that are representative of the most common words in a language. This method could be considered a good starting point for word selection. However, this method of selection is appropriate for languages where there are well-developed dictionaries and word list resources e.g. The English Thorndike's list of word frequency, used in the (Hirsh, 1952) study. The South African Zulu language literature has not yet come to consensus in so far as the most common words spoken in Zulu are concerned ( $R$. Bailey, personal communication, September, 2006). Therefore, the paucity of such resources in the African languages has resulted in the researcher considering the present methods of word selection, by utilizing tertiary educators and Zulu language interpreters.

The use of speakers of the language to identify common words as indicated in the present study implies that the words generated may have more relevance in present times. Generating a word pool from the speakers of a language at the time would naturally result in the words being more familiar than if words were selected out of a dictionary that might have been developed many years prior to the study. This also supports the notion that vocabulary does indeed possess a "shelf life" and that all living languages change over time (Fromkin \& Rodmin, 1993).

A closer analysis of the common words selected indicate that a small percentage of the words $(3.8 \%)$ or $(5 / 131)$ were words borrowed from English e.g. "wina". Thus, indicating that all words considered common may not be completely indigenous to the language. The inclusion of the borrowing merely enhances the relevance of the list in terms being common, to the diverse Zulu-speaking clinical population. The support for the inclusion of borrowing in a language is limited to what linguists and language rights activists state i.e. that languages have developed over the years through "liberal borrowings from neighboring languages" (Alexander, 2006, p. 3). Zulu should be no different, especially when one considers the present state of globalization within the South African context. The present researcher argues that while an indigenous word list for Zulu is relevant, the content of the words list must be highly familiar to the population for which it is meant for. This argument also illustrates that researchers could possibly run the risk of excluding highly familiar and common words should their methodological design follow rigid and traditional methods of relying on dictionaries and standard dialects. These standard dialects are often spoken on newscasts for television and radio, which would exclude words that may be borrowed from another language.

The results obtained in objective one of the study, therefore, indicate that careful consideration of the linguistic structure of that language is certainly relevant in word list development. In addition, this study demonstrated that in the development phase of a word list, the researcher has to develop astute methods of generating the word list. While adhering to linguistic and audiological principles for word choices, reliability and validity in the data were ensured. Therefore, in order to fulfill objective two, six linguists were asked to rate the 131 words on a three point Likert scale for the following criteria i.e. familiarity, phonetic dissimilarity and tonal patterns of the words. Words included in objective two of the study had to achieve a mean rating score of 1.5 or less on all criteria. The scores of five of the six linguists were analyzed, as one linguist did not complete the criterion on tone and many of the words in the other two sections were omitted. Therefore, in terms of reliability of the data, the ratings from five linguists were analyzed.

In terms of familiarity, the majority $(106 / 131)(81 \%)$ of the words obtained a mean rank of less than 1.5 on the Likert rating scale across all five raters. Eighty one percent of the words in the pre-liminary list were regarded as very familiar and a mere $19 \%$ were indicated as being unfamiliar. However, the final selection of the words also depended on the mean ranks for tone and phonetic dissimilarity as discussed below.

In terms of tone of the words a larger number of words obtained a mean score greater than $1.5(45 \%)$ compared to the results obtained for familiarity. Fifty five percent of the words obtained a score of less than 1.5 on the Likert scale. These words were thus indicated as low tone words. The remaining $45 \%$ were considered high tone verbs. For the purposes of this study the low tone verbs were selected.

In terms of the results obtained for phonetic dissimilarity, the majority $(102 / 131)$ of the words were rated as phonetically dissimilar. However, there were a small percentage of words that were highly similar in their phonetic structure. Phonetic dissimilarity was determined by the focusing differences in consonant and vowel structures within each word.

Careful analysis of each of the mean ranks for each criterion resulted in the selection of 58 words. The 73 words that did not meet the criteria were excluded from the study. The 58 selected words satisfied the criteria for familiarity, tone and phonetic dissimilarity and are included in Appendix C.

In addition to the above result, the researcher measured the reliability of the ratings across all five linguists. The test statistic in Table 3 indicates that a W score 0.823 was obtained for the criterion of familiarity. This implies that a very good agreement existed among all five raters. The agreement is noted at 0.05 level of confidence (Assyp.Sig $=0.000<0.05$ ). Therefore, with $95 \%$ confidence there was little difference among the raters with regard to the rating of the words for familiarity. However, the coefficient of concordance for criterion of tone was 0.431 which implies that there was a moderate agreement among the 5 raters for the criteria of tone.

These results suggest that there were also no significant differences in the rating of the tone of the words, even though the agreement was moderate as compared to very good agreement in the familiarity aspect. Similarly the coefficient of concordance of 0.665 for phonetic dissimilarity which implied that there is good agreement among the 5 raters at the 0.05 level of significance (asymp. sig. $=0.000<0.05$ ).

\begin{tabular}{|l|l|l|l|}
\hline & Famtlarity & \multicolumn{1}{c|}{$\begin{array}{c}\text { Phonetic } \\
\text { dissimilarity }\end{array}$} & Tone \\
\hline $\mathbf{N}^{\star}$ & 5 & 5 & 5 \\
\hline Kendall's W & 0.823 & 0.431 & .665 \\
\hline Chi Square & 481.488 & 252.067 & 388.906 \\
\hline Df & 117 & 117 & 117 \\
\hline Asym. Sig & .000 & .000 & .000 \\
\hline
\end{tabular}

* Number of raters 
Table 3: Test statistic for the Kendall's Co-efficient of Concordance for familiarity, phonetic dissimilarity and tone

The researcher could therefore accept the contention that the 58 words rated as familiar, low tone and phonetically dissimilar by the 5 raters were reliable. These 58 words were further assessed for the criterion of homogeneity with respect to audibility using logistic regress ion analysis. However the details of this aim of the study are beyond the scope of this paper and would be presented in a subsequent paper. This high percentage of words $(81 \%)$ that were rated as very familiar confirms that these words identified by participants in objective 1 are common to the KZN Zulu speaking population. This result also reinforces the contention that words considered most common in everyday environment can be considered to be the most familiar words in that environment (Wilson \& Margolis, 1983). With regard to familiarity of words in other studies, it would appear that researchers have relied on various methods for the selection of familiar words. Traditionally Hirsh et al. (1952) utilized a judging system whereby English words were rated on a Likert scale. A recent study conducted on Mandrin speakers selected familiar words on the basis of dictionaries that existed in their language. In addition the use of judges was only considered for screening the word list for culturally insensitive words which were deemed unfamiliar. However, in the present study taking into account the paucity of dictionaries that indicates the most frequently occurring bisyllabic verbs in Zulu, having all the 131 words rated for familiarity by linguistic experts was a suitable alternative.

While the mean ratings for the familiarity of the words indicated that the majority of the words were highly familiar, the selection of the words for the study was also dependent on the tone and phonetic dissimilarity of the words. Low tone verbs were introduced as an adapted criterion for SRT words in Zulu. This criterion was introduced after careful analysis of the linguistics of Zulu. Zulu has only one main stress in most words, which prevents the language from having spondee words. However, after consultation with a linguist of Zulu it would appear that low tone verbs allows for the lengthening of the penultimate syllable, thus allowing for the final syllable to gain prominence. Tone is a complex phenomenon in Zulu and even linguists and users of the language have grave difficulty identifying tonal patterns (R. Bailey, personal communication, February, 2004). The complexity of the tone of Zulu is also expressed by Buell (2004). There are "scant sources for lexical tone in Zulu" (Buell, 2004, p. 1).

This could possibly explain the results obtained within the present study with regards to the rating of the tone of the words. The moderate level of agreement among the linguists, i.e. the Kendall's w score of 0.431 is indicative that even linguistic experts differ with regard to low tone and high tone verbs. However, the agreement is still considered reliable at $95 \%$ of confidence. These results merely confirm the complexity of languages and also illustrate that developing a word list with adapted criteria requires extensive resources and expertise. The $55 \%$ of the words indicated as low tone words were verified against a list of Zulu verbs with tone markers compiled by Buell (2004).

Further, within the present study the use of low tone verbs limited the variability of the phonemes among the words. Low tone verbs generally end in the same vowel/a/ e.g. Bhala, Bhema, Gqoka. Hence, the second syllable of most verbs in the list could potentially be very similar in phoneme structure. This suggests that words in the final list for Zulu would possibly have variability of consonants and vowels in the first syllable, but variability would be limited in the second syllable as illustrated in the example. However, Zulu has a much more complicated consonant system than English. In addition to the known sound system like fricatives, stops and plosives, Zulu has the prominent click sounds. The inclusion of the click sounds in the phoneme distribution of the words contributes to consonant variability in the words. Thus, within the present study, because of the importance of low tone verbs, the researcher concentrated on the variability of the consonant structure and to lesser extent on the variability of the vowel system. This standpoint was supported by the linguistic choices made within the study.

The overall agreement among the raters for the criteria of familiarity, tone and phonetic dissimilarity provided the necessary reliability with regard to the choice of words for the study. The choice of words, using the adapted and modified criterion discussed above, is a clear indication that the words selected represent the linguistic structure of the Zulu language, the acoustic properties of Zulu and the sociolinguistic aspects. This principle is the inherent theoretical premise that foregrounded this study. The clinical usage of the test tool was also dependent on the very important criterion of homogeneity of audibility that was used to assess the words for inclusion into Phase two of the study which is documented in Panday (2006).

\section{CONCLUSION AND RECOMMENDATIONS}

This study therefore concluded that 131 words were identified as common bisyllabic words for the adult ZFLS. Descriptive statistics indicated that the majority of the words identified were bisyllabic verbs which was in accordance with the structure of Zulu. Objective two of the study concluded that 58/13 I words satisfied the criterion of familiarity, phonetic dissimilarity and low tone verbs. These words were rated on three point Likert scale by linguistic experts. The Kendall's coefficient of concordance was found to be very good for familiarity, moderate for tone and good for phonetic dissimilarity. These were obtained at $95 \%$ level of confidence. Therefore the results obtained were reliable. These words can be used to form a suitable SRT word list for Zulu First Language Speakers.

Therefore the following recommendations are made i.e.

- The present paper can be used as an example of how words could be developed in mother tongue languages by adhering to both the audiological and linguistic principles inherent in speech reception testing.

- The present paper could also serve as a guideline towards the development of linguistic relevant SRT materials in other African languages locally and internationally.

- The developed word list was assessed for its application to a normative clinical population as described in Panday (2006). The final word list therefore could be assessed for application on a varied clinical population.

- The final word list developed in Panday (2006) may be used clinically with caution via recorded material for the assessment of hearing for speech for the adult ZFLS.

Further clinical and research implication for the test tool is available in Panday (2006).

\section{ACKNOWLEDGEMENTS}

This article is the culmination of thesis submitted to the University of Kwa Zulu- natal by the first author for the require- 


\section{REFERENCES}

akmajian, A., Demers, R. A., Farmer, A. K., Harnish. R. M. (1990). An introduction to language and communication. Massachusetts: Library of Congress Cataloging.

Alexander, N. (2006). Language policy and planning in the new South Africa. Retrieved December 12, 2006 from www.codesria.org/links/publications/ asr_lfull/alexander.pdf

American Speech-Language-Hearing Association. (1988). Guidelines for determining the threshold for speech. $A S H A, 3,85-88$.

Ashoor, A. A., \& Prochazka, T. (1985). Saudi Arabic speech audiometry in children. British Journal of Audiology, 19, 229-238.

Balkisson, Y. (2001). Speech discrimination testing: Towards the development of wordlists for Zulu-first language speaking children. Unpublished undergraduate dissertation. University of Durban-Westville, Durban, South Africa.

Bortz, M. (1992). Community work project in Gazankulu: A community-based training experience. The South African Journal of Communication Disorders, $39,64-67$

Buell, L. (2004). Zulu verb lists with tones. Retrieved September 15, 2006, from www.fizzylogic.com/users/bulbul/school/zuluverblist.html.

Carhart, R. (1965). Basic principles of speech audiometry. Acta Otolaryngologica, 40, 62-71

Chetty, S. (1990). An investigation into the effectiveness of two Zulu word lists in establishing speech reception thresholds in normal hearing bilingual (English/Zulu subjects). Unpublished undergraduate dissertation. University of Durban-Westville, Durban, South Africa.

Cope, A.T. (1982). A comprehensive course in the Zulu language. Durban Howard College, University of Natal.

Criag, C. H. (1997). Spoken language processing. In G. D. Chermack, \& F. E. Musiek (Eds.), Central auditory processing disorders: New perspectives (pp. 71-90). London: Singular Publishing Group.

Doke, C. M. (1939). Textbook of Zulu Grammar. RSA: Longman Green Company Ltd.

Fromkin, V. \& Rodmin, R. (1993). An introduction to language. New York:Holt, Rinehart \& Winston lnc.

Gelfand, S. A. (1997). Essentials of audiology. New York: Thieme Medical Publishers

Grimes, J. (1992). UCLA language materials Zulu language profile. Retrieved November 02, 2004, from http://www.Imp.ucla.edu/profiles/profz01.htm.

Hirsh, I.J., Silverman, S. R., Reynolds, E. G., Eldert, E., \& Benson, R.W. (1952). Development of materials for speech audiometry. Journal of Speech and Hearing Disorders, 17, 332-337.

Hodgeson, W. R. (1980). Basic audiological evaluation. Baltimore: Williams and Wilkins.

Hudgins, C.V., Hawkins, J. E., Karlin, J. E., \& Stevens, S. S. (1947). The development of recorded auditory tests for measuring hearing loss for speech. Laryngoscope, 57, 57-89.

Jacobson, M.C., Trail, A. (1986). Assessment of speech intelligibility in Southeastern Bantu languages: Critical considerations. The South African Journal of Communication Disorders, 33

John, D.C. (1990). A comparison of spondee threshold and digit thresholds obtained in a sample of normal hearing English and Zulu speaking students. Unpublished undergraduate research, University of Durban-Westville, Durban, South Africa.

Kendall, M.G., Babington Smith, B. (1939). The problem of m rankings. Annals of Mathematical Statistics, 10, 257-287.
Kent, R. (1992). Auditory processing of speech. In J. Katz, N.A. Stecker \& D. Henderson (Eds.), Central auditory processing: A transdisciplinary view (pp. 3-96). St Louis: Mosby

Knight, J. (1997). Speech tests in some languages other than English. In M.Martin (Ed.), Speech Audiometry: (pp 315-324). London: Whurr Publishers.

Kruger, B., \& Kruger, F. M. (1997). Speech audiometry in USA. In M. Martin (Ed.), Speech Audiometry (pp. 233-277). London: Whurr Publishers.

Leedy, P. D., \& Ormrod, J. E. (2005). Practical research. New Jersey: Prentice Hall.

Lyregaard, P. (1997). Towards a theory of Speech Audiometry Tests. In M.Martin (Ed.), Speech Audiometry (pp. 34-62). London: Whurr Publishers.

Madden, S. (1996). Speech discrimination testing of Xhosa adults in the Western Cape: Survey research findings regarding common clinical practice in Speech Audiometry testing for Xhosa first Language Xhosa speakers and the compilation of 8 new 25 word lists. Unpublished undergraduate dissertation, University of CapeTown, South Africa.

Martin, F.N. (1997). Speech Audiometry $2^{\text {nd }}$ ed). London: Whurr publishers.

Mcmillan, J. H., \& Schumacher, S.S. (2001). Research in education, a conceptual introduction. USA: Addison Wesley Longman, Inc.

Nissen, S.L., Harris, R. W., Jennings, L. J., Eggert, D. L., \& Buck, H. (2005). Psychometrically equivalent trisyllabic words for speech reception threshold testing in Mandarin. International Journal of Audiology, 44, 391-399.

Pillay, M., Kathard, H., \& Samuel, M. (1997). The curriculum of practice. The South African Journal of Communication Disorders, 44,109-117.

Panday, S. (2006). The development of a Zulu Speech Reception threshold test for Zulu ' First Language Speakers in Kwa Zulu-Natal. Unpublished masters dissertation, University of kwa Zulu- Natal, South Africa

Plant, G. (1990). The Development of speech tests in Aboriginal languages. Australian Journal of Audiology, 13, 30-40.

Population Census. (2001). Languages of South Africa. Retrieved December 09, 2006 from Statistics South Africa. www.southafrica.info/ess_info/ sa_glance/demographics/language.htm

Punch, J. L., \& Howard, M.T. (1985). Spondee recognition threshold as a function of set size. Journal of Speech, Language \& Hearing Disorders, 50,120125.

Ramkissoon, 1. (2000). Speech reception thresholds for non-native speakers of English: Digit pairs vs spondee words. Unpublished doctoral dissertation, University of Illinois, Urbana Champaign, Illinois.

Ramkissoon, I., Proctor, A., Lansing, C., Bilger, R. C. (2002). Digit speech recognition threshold (SRT) for non-native speakers of English. American Journal of Audiology, 11, 23-28.

Roeser, J. R., Valante, M., \& Horsford-Dunn, H. (2000). Audiology Diagnosis. USA: Thieme Medical Publishers.

Rudmin, F. (1987). Speech reception threshold for digits. Journal of Auditory Research, 27, 15-21.

Rycroft, D. K., \& Ngcobo, A. B. (1979). Say it in Zulu. Pietermarizburg: University of Natal Press.

Silman, S., \& Silverman, C. A. (1991). Audiology diagnosis. Principles an practice. New York: Academic press, Inc.

Wilson, R. H., \& Margolis, R. H. (1983). Measurements of auditory thresholds or speech stimuli. In D.F. Konkle \& W.F. Rintleman (Eds.), Principles of Speech Audiometry (pp. 79-126). Baltimore: Academic Press.

Young, J.R., Dudley, B., \& Gunter, M. B. (1982). Thresholds and psychometric functions of the individual spondaic words. Journal of Speech and Hearing Research, 25, 586-593. 


\section{APPENDIX A}

Identification Schedule: Adapted from Balkisson (2001)

Please list the most commonly used bi-syllabic Zulu words used by Zulu First Language Speakers in KZN. Each individual must fill a minimum of 100 words

\begin{tabular}{|c|c|c|c|}
\hline No & Commonly used Bi -syllablc Zulu words & No & Commonly used Bi -syllabic Zulu words \\
\hline 1 & & 51 & \\
\hline 2 & & 52 & \\
\hline 3 & & 53 & . \\
\hline 4 & & 54 & \\
\hline 5 & & 55 & \\
\hline 6 & & 56 & \\
\hline 7 & & 57 & \\
\hline 8 & & 58 & \\
\hline 9 & & 59 & \\
\hline 10 & & 60 & \\
\hline 11 & & 61 & \\
\hline 12 & & 62 & \\
\hline 13 & & 63 & \\
\hline 14 & & 64 & \\
\hline 15 & & 65 & \\
\hline 16 & & 66 & \\
\hline 17 & & 67 & \\
\hline 18 & & 68 & \\
\hline $\begin{array}{l}19 \\
\end{array}$ & & 69 & \\
\hline 20 & & 70 & \\
\hline 21 & & 71 & \\
\hline 22 & & 72 & \\
\hline 23 & & 73 & \\
\hline 24 & & 74 & \\
\hline 25 & & 75 & \\
\hline 26 & & 76 & \\
\hline 27 & & 77 & \\
\hline 28 & & 78 & \\
\hline 29 & & 79 & 1 \\
\hline 30 & & 80 & 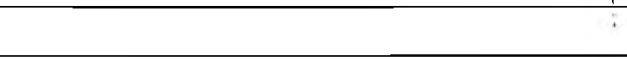 \\
\hline 31 & & 81 & ! \\
\hline 32 & & 82 & 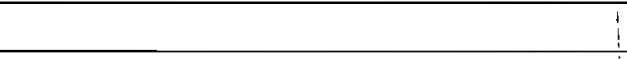 \\
\hline 33 & & 83 & \\
\hline 34 & & 84 & \\
\hline 35 & & 85 & 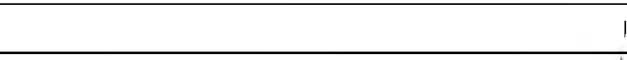 \\
\hline 36 & & 86 & 4 \\
\hline 37 & & 87 & \\
\hline 38 & & 88 & \\
\hline \begin{tabular}{|l|}
39 \\
\end{tabular} & & 89 & \\
\hline 40 & & 90 & \\
\hline 41. & & 91 & 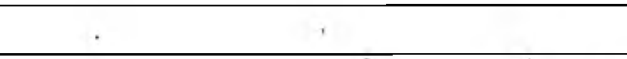 \\
\hline 42 & & \begin{tabular}{l|}
92 \\
\end{tabular} & 1 \\
\hline 43 & & 93 & . \\
\hline \begin{tabular}{l|l}
44 \\
\end{tabular} & & 94 & $\therefore$ \\
\hline 45 & & 95 & $\gamma$ \\
\hline \begin{tabular}{l|l}
46 \\
\end{tabular} & & 96 & 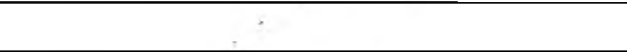 \\
\hline $\begin{array}{ll}47 \\
\end{array}$ & & 97 & \\
\hline 48 & & 98 & ' \\
\hline 49 & & 99 & \\
\hline 50 & & 100 & \\
\hline
\end{tabular}




\section{APPENDIX B}

A description of the words obtained per participant for objective one

\begin{tabular}{|c|c|c|}
\hline $\begin{array}{l}\text { Words suggested } \\
\text { by any of the two participants }\end{array}$ & $\begin{array}{l}\text { Words suggested } \\
\text { by any of the three participants }\end{array}$ & $\begin{array}{l}\text { Words suggested } \\
\text { by any of the four participants }\end{array}$ \\
\hline 1.Bhala & Bona & Bhaka \\
\hline 2.Bhema & Banga & Biza \\
\hline 3.Buza & Bheka & Bola \\
\hline 4.cela & Cwewa & Cacha \\
\hline 5.chela & Dinga & Cinga \\
\hline 6.dansa & Dlala & Donsa \\
\hline 7.duda & Faka & Gcina \\
\hline 8.dula & Futhi & Geza \\
\hline 9. fika & Ganga & Hamba \\
\hline 10.funa & Goba & Khipa \\
\hline 11.funda & Gxeka & Landa \\
\hline 12.finya & Hleka & Netha \\
\hline 13.gcaca & Hoya & Ndiza \\
\hline 14.gqoka & Hlala & Pheka \\
\hline 15.hola & Hluba & Phuma \\
\hline 16.jika & Hlupha & Shaya \\
\hline 17jula & Hlenga & Siza \\
\hline 18jaha & Jeza & Shada \\
\hline 19khiye & Khanya & Thatha \\
\hline 20.khala & Kheta & Vala \\
\hline 21.klekha & Khola & Woza \\
\hline 22letha & Khaba & Yifa \\
\hline 23.lima & Lala & \\
\hline 24.loya & Linda & \\
\hline 25.lapha & Luma & \\
\hline 26.minya & Lunga & \\
\hline 27.ngena & Manje & \\
\hline 28.nuka & Mina & \\
\hline 29.nyanga & Mila & \\
\hline 30phansi & Muva & \\
\hline 31phezu & Ncama & \\
\hline 32.phuza & Nyama & \\
\hline 33qeda & Phupha & \\
\hline 34.qonda & Phosa & \\
\hline 35.qina & Phapha & \\
\hline 36.senga & Pheza & \\
\hline 37.sula & Qala & \\
\hline 38.sefa & Qoba & \\
\hline 39.shiya & Quela & \\
\hline 40.Sika & Qhaqha & \\
\hline $41 . \sin a$ & Qaqa & \\
\hline 42.susa & Shesha & \\
\hline 43. Thola & Thenga & \\
\hline 44. Thula & Thanda & \\
\hline 45.thela & Vuka & \\
\hline 46.tshala & Vula & \\
\hline 47. veza & Vuma & \\
\hline 48.wawa & Washa & \\
\hline $49 . \times 0 \times a$ & Wina & \\
\hline 50. xola & Xosha & \\
\hline 51. Yeka & Yeba & \\
\hline 52.Yanga & Yosa & \\
\hline 53.yenza & & \\
\hline \multicolumn{3}{|l|}{ 54.yona } \\
\hline \multicolumn{3}{|l|}{ 55.zakhe } \\
\hline \multicolumn{3}{|l|}{ 56.zosha } \\
\hline 57.Zabo & & \\
\hline
\end{tabular}




\section{APPENDIX C}

The fifty eight words selected according to the criteria of familiarity, phonetic dissimilarity and tone

\begin{tabular}{|c|c|c|c|}
\hline banga & hlala & loya & veza \\
\hline bheka & hleka & lunga & vula \\
\hline bhema & hlenga & minya & vuma \\
\hline chela & hluba & pheka & washa \\
\hline cinga & hola & phonsa & wina \\
\hline dansa & jaha & qoba & xola \\
\hline dinga & jeza & sefa & yanga \\
\hline donsa & khaba & shada & yeba \\
\hline faka & khanya & shaya & yeka \\
\hline finya & kheta & thanda & yenza \\
\hline geza & khipa & thatha & yifa \\
\hline goba & landa & thela & yona \\
\hline gonda & letha & thenga & yosa \\
\hline gqoka & lima & thola & \\
\hline gxeka & linda & vala & \\
\hline
\end{tabular}




\section{NATURE OF PUBLICATION}

The South African Journal of Communication Disorders publishes reports and papers concerned with research, and critically evaluative theoretical and philosophical conceptual issues dealing with aspects of human communication and its disorders, dysphagia, service provision, training and policy. The Journal will accept the following three types of manuscripts:

- Research manuscripts defined as reports based on qualitative or quantitative research.

Original general manuscripts which are reports of work usually, but not exclusively, theoretical in nature and regarded as providing a significant, critically evaluative contribution to the field of human communication and its disorders and/or dysphagia.

- Review manuscripts which are usually written by authors invited by the Journal's editorial team to comment, express opinions and or critically evaluate a topic.

The Journal will not accept material which has been published elsewhere or that is currently under review by other publications.

\section{MANUSCRIPT SUBMISSION \& STYLE REQUIREMENTS}

- Manuscripts must he accompanied by a covering letter providing the author's address, telephone and fax numbers and e-mail address.

THREE printed copies of the manuscript must be submitted.

- The title page of ONE copy must contain:

Title of the manuscript.

Full names of the authors.

Institutional affiliation.

Abstract of the manuscript in the language of the manuscript.

- The title page of the remaining TWO copies must NOT contain the author(s) names or institutional affiliations.

- ONE exact electronic copy of the title page and manuscript on disk must be submitted. Filenames must include the first author's initials and a clearly identifiable key word and must he type-written on the last line of the last page of the Reference list (for retrieval purposes only).

- An electronic copy of the title page and manuscript must be emailed to admin@saslha.co.za. The Editor-in-Chief and/or the South African Speech-Language-Hearing Association (SASLHA) administrator will acknowledge receipt of the manuscript within a maximum of 7 days. If at this stage, no acknowledgement has been received by the author, the author is kindly requested to follow this up with the SASLHA office.

- MS Word must be used for the text. MS Word or MS PowerPoint should be used for figures, and MS Excel for tables.

- Manuscripts must be in double spacing and in a font size of 12 .

- Manuscripts must be on A4 pages in double spacing and in a font size of 12

- Filenames must include the first author's initials and a clearly identifiable key word.

- Manuscripts must not exceed 30 pages.

- The order of the manuscript shculd be: title page, abstract and key words, text, references, tables, legends, and figures.

- Each manuscript must contain an English abstract of no more than 200 words with 5-7 key words.

- Strict adherence to the Publication Manual of the American Psychological Association ( $5^{\text {th }}$ ed., 2001) is required.

- Headings are NOT NUMBERED. The order of importance is indicated as follows:

- Main heading in capitals and bold print

- Sub-headings in upper and lower case and bold

- Sub-subheadings in upper and lower case bold and italic print.

- Sub-sub-sub-heading in upper and lower case italic print.

Major headings, where applicable, must be in the order of INTRODUCTION, METHOD, RESULTS, DISCUSSION, CONCLUSION, ACKNOWLEDGEMENTS, and REFERENCES.

- All paragraphs should be indented.

All tables, figures and illustrations must be numbered and provided with titles.

- The title of tables, which appear above, and of figures, which appear below, must be concise but explanatory.

- Allow for 50-75\% reduction in printing of tables, figures and illustrations.

- Each table, figure or illustration must appear on a SEPARATE page.

- Do not include more than 10 tables, figures or illustrations.

Colour graphics are NOT preferred. If submitted, extra cost of colour reproduction and printing must be covered by the author prior to publication.

A short running title should be listed at the top left-hand corner of the title page. Any information about grants or other financial support should be supplied as an unnumbered footnote to the manuscript title.
- Graphics, audio and/or video files (not exceeding $2 \mathrm{MB}$ ) may be submitted for future publication as an electronic online Journal Consult the Editor-in-Chief regarding required file formats.

- Authors must use gender-, race-, and creed-inclusive language.

- Authors must ensure adherence to national and/or internationa ethical codes.

- British spelling (e.g. centralise not centralize, behaviour not behavior) is preferred.

\section{REFERENCING}

- References must be cited in the text by author's name and the date, e.g. Van Riper (1971).

- Where there are more than two authors, after the first occurrence, et al. may be used.

- The names of all authors must appear in the Reference List, which must be listed in strict alphabetical order in triple spacing at the end of the manuscript.

- All references must be included in the List, including secondary sources.

- Only acceptable abbreviations of journals may be used, (see DSI-1 ABSTRACTS, October; or The World List of Scientific Periodicals).

- Author(s) should use references that reflect an international diversity among authors of both source articles and cited articles.

- The number of references should not exceed 30, unless specifically warranted.

\section{Examples}

Locke, J.L. (1983). Clinical Psychology: The explanation and treatment of speech sound disorders. J. Speech Hear Disord., 48 339-341.

Penrod, J.P. (1985). Speech discrimination testing. In J. Katz (Ed.) Handbook of clinical audiology ( $3^{\text {rd }}$ ed.). Baltimore: Williams \& Wilkins. Davis, G. \& Wilcox, M.J. (1985). Adult aphasia rehabilitation: Applied pragmatics. San Diego, CA: College-Hill.

\section{EDITING}

- Manuscripts must be corrected for grammar and style prior to submission.

- Only manuscripts complying with the above requirements will be accepted for review.

\section{REVIEWING SYSTEM}

- The double-blind peer review system is employed as a method of quality control of this publication and ensures that author(s) and reviewers do not know each others' names.

- Each manuscript is sent to two independent reviewers, selected according to their area of expertise, to assess the quality of the manuscript's scientific and technical content.

- Author(s) must ensure that the manuscript does not contain information/clues as to the identity of the author(s).

- The Editor-in-Chief retains the final responsibility for decisions regarding revision, acceptance or rejection of the manuscript. This process is usually done in consultation with the manuscript's editor and/or the editorial team, as necessary.

\section{DEADLINE FOR CONTRIBUTIONS. $28^{\text {th }} / 29^{\text {th }}$ February each year}

PUBliCATION FEe: Authors will be expected to pay a publication fee. The exact amount is determined by printing costs.

QUERIES AND CORRESPONDENCE: should be addressed to The Editor-in-Chief, South African Journal of Communication Disorders, South African Speech-Language-Hearing Association, PO Box 10813, Linton Grange, 6015, South Africa. Email SASLHA at admin@saslha.co.za for the current Editor-in-Chief's email address.

Author's Responsibility: The South African Journal of Communication Disorders is not responsible for authors' views and does not endorse any of the products or materials advertised in the Journal.

Copyright: The copyright of all manuscripts printed in The South African Journal of Communication Disorders is reserved by The South African Speech-Language-Hearing Association (SASLHA).

\section{Editorial Board}

Editor-in-Chief: Dr Mershen Pillay

Editors: Prof Harsha Kathard, Dr Elsie Naude, Prof Eleanor Ross

Editor (assistant): Dr. Michelle Pascoe (editor-elect 2008)

Technical Editor: Ms Carmen Milton 